\title{
Epidemiological coherency of vulpine dirofilariosis in environmental conditions of Slovakia
}

\author{
Z. HURNÍKOVÁ1, 2, * M. MITERPÁKOVÁ1 , G. ZALEŚNY³
}

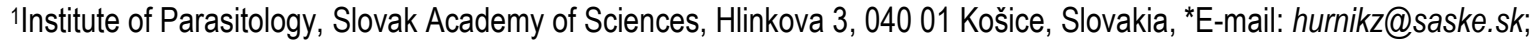
2Dpt. of Parasitology, University of Veterinary Medicine and Pharmacy in Košice, Komenského 73, 04181 Košice, Slovakia; 3Institute of Biology, Department of Invertebrate Systematics and Ecology, Wrocław University of Environmental and Life Sciences, Kożuchowska 5b, 51-631 Wrocław, Poland
\end{abstract}

\section{Article info}

Received May 20, 2014

Accepted September 23, 2014

\begin{abstract}
Summary
Dirofilariosis belongs to zoonotic vector-borne diseases with fastest spread into new areas caused by extreme weather and seasonal changes in climate. In Slovakia, Dirofilaria spp. parasites affect more than $30 \%$ of dogs living in endemic regions in southern parts of territory, however, data on wildlife circulation of this parasite are still scarce. In order to clarify the role of red fox (Vulpes vulpes) as the most abundant canid species in Europe in maintaining the parasite in natural foci, an initial survey of dirofilariosis in this carnivore species was conducted in Slovakia. The samples of 183 red foxes hunted in 2007 - 2009 in regions of South-Eastern and Northern Slovakia with different geographical and climate characteristics were examined by means of PCR method using specific $D$. repens, $D$. immitis and Acantocheilonema recognitum primers. The DNA was isolated from spleen samples using commercial kit and PCR approach was used for diagnostics. After amplification selected products were purified and sequenced to elucidate any homologies with previously deposited sequences in Gen Bank. The results showed 105 out of 183 examined specimens (57.4 \%) being infected, with great regional differences in prevalence. Phylogenetic relationships within Dirofilaria species indicate that obtained isolates belong to $D$. repens. The results confirmed the role of red foxes as the reservoir of parasite. Herein, epidemiological factors that may be coherent with the Dirofilaria parasites distribution and circulation in wildlife and implications in risk assessment and prevention for domestic animals and human are discussed.
\end{abstract}

Keywords: Canidae; red fox; Vulpes vulpes; Dirofilaria; epidemiology

\section{Introduction}

The incidence and spread of vector-borne diseases is linked to extreme weather events and seasonal changes in micro- and macroclimate. According to Intergovernmental Panel on Climate Change (2007) the global surface temperature increased approximately by $0.3-0.6^{\circ} \mathrm{C}$ during the 20th century with considerable effect on the hydrological cycle (heavy rainfalls, floods, mega storms, heat waves, droughts) and biosphere (deforestation, desertification, coral bleaching) as well as pole ward and upward shifts in ranges in plant and animal species. Variations in biodiversity together with anthropogenic effects on ecosystems may be accompanied by spread of tropical insects followed by pathogen transmission (Zell, 2004). As arthropod vectors, their reproduction and mortality are significantly responsible to seasonal climate changes, the dynamics and transmission patterns of vector-borne diseases is very likely be influenced.
This scenario begins in recent years to take place in Europe, where mainly due to warming and frequent flooding accompanied by increased incidence of mosquitoes several vector-borne diseases began to spread, including filarioses. Disease agents in Europe are several filarial species (Filaroidea) that are infectious for carnivores, i.e. Dirofilaria immitis, D. repens, Acantocheilonema recognitum, $A$. dracunculoides and Cercopithifilaria grassi (Genchi et al., 2011). Their transmission is associated with arthropods, which in the parasite life cycle play the role of both, vector and intermediate host. The most frequently occurring species within the European territory are $D$. immitis and $D$. repens transmitted by different types of mosquitoes (e.g. Aedes spp., Anopheles spp., Culex spp.). Definitive hosts constitute carnivores, with the greatest contribution of representatives of the family Canidae. Humans can become an occasional host; however the incidence of human infections in Europe has markedly accrued recently. Dirofilaria immitis, with a cosmopolitan distribu- 
tion, and $D$. repens, only reported in the Old World, are the main causative agents of zoonotic filariosis. Adult parasite living in the organism of definitive host produces larval stages (microfilariae) that circulate in the blood. During blood sucking microfilariae get into the mosquitoes body where they develop to infectious L3 larvae and during repeated blood sucking the infective stages enter next host, where they shed and mature to adults. Adult worms from both species live in the pulmonary artery and in subcutaneous tissue of dogs and cats, resulting in the production of blood-circulating microfilariae in dogs, while amicrofilaremic infections are common in felines. In humans, worms cannot reach maturity, and preadult worms are responsible for pulmonary (D. immitis) and for subcutaneous or ocular (D. repens) dirofilariosis (Simon et al., 2009).

Short period of development during seasons of high ambient temperatures allows releasing of several generations and increases potential parasite temporal availability which escalates the risk of infection. Therefore, this parasite formerly occurred endemically mainly in regions with tropical, subtropical and prevailingly warm climate. As a result of climate change, global warming and frequent flooding followed by an increased incidence of mosquitoes extended the parasite range also to other areas of Europe (Morgan \& Wall, 2009).

The incidence of dirofilariosis agents and the emergence of new endemic areas were recorded in recent decade in several European countries with mild climate, such as Bulgaria, Serbia, Hungary, Austria, Czech Republic, Poland, Russia, or Latvia (Simon et al., 2009; Fók, 2012). The first occurrence of the disease in dogs in Slovakia was recorded in the western part of territory in 2005 (Svobodová et al., 2005). The results of systematic survey performed in 2007 showed a high prevalence (34.5\%) in dogs, originating from lowland areas of southwestern and south-eastern Slovakia, characterized by the warmest climate in our country (Miterpáková et al., 2008).

Although in recent years intensive research on dirofilariosis in domestic carnivores (dogs, cats) has been in the progress, data on parasite distribution in populations of wild carnivores are rare. Red fox (Vulpes vulpes) is the most abundant species of wild canid predators in major part of Europe and often occurs in the vicinity of human settlements. Like other wild and domestic carnivores foxes may become infected with several species of filarial nematodes. Since in Slovakia $D$. repens and $D$. immitis infections in dogs were reported, we conducted an initial survey of dirofilariosis in red foxes in geographically and climatically different areas in order to clarify their role in maintaining the parasite in natural foci.

\section{Materials and Methods}

\section{Studied areas}

Foxes were hunted in 2007 - 2009 in regions of south-eastern and northern Slovakia with different geographical and climate characteristics (Fig. 1).

The major part of south-eastern Slovakia represents the Eastern Slovak Lowland, expanding on $2500 \mathrm{~km}^{2}$ bordering with Ukraine and Hungary $\left(49^{\circ} 11^{\prime}-48^{\circ} 24^{\prime}, 21^{\circ} 51^{\prime}-22^{\circ} 12^{\prime} \mathrm{E}\right)$. The altitude of the area is $95-200 \mathrm{~m}$ above sea level. Region belongs to the mild climatic zone and has generally a warm and fairly dry cli- mate with an average annual air temperature of about $9-10^{\circ} \mathrm{C}$, with 50 - 70 summer days and warmest month being July with average temperature $+19.7^{\circ} \mathrm{C}$. The annual rainfall achieves 600 up to $750 \mathrm{~mm}$ and profound rainstorms often occur, causing intensive floods. The area is characterized by fan shaped stream network with important rivers Bodrog and its tributaries Ondava, Laborec, Latorica, Uh and Topla. A big water reservoir Zemplínska Šrrava $\left(33 \mathrm{~km}^{2}\right)$ and system of protective dikes and drainage canals have been built to prevent frequent floods. Lowland meadows, grasslands, pastures and fields with swamps and swamp forests prevail in the landscape, with protected habitats in nature preserves. Aforementioned conditions are associated with recurring mosquito calamities.

Northern Slovakia is mountainous and coldest area of Slovakia $\left(48^{\circ} 47^{\prime}-49^{\circ} 53^{\prime}, 18^{\circ} 48^{\prime}-22^{\circ} 51^{\prime} \mathrm{E}\right)$ with average elevations 300 - 800 above sea level and mountain peaks reaching up to 2655 $\mathrm{m}$ a.s.I. (Gerlach). More than $50 \%$ of the landscape comprise forest complex, land principally occupied by agriculture with significant areas of natural vegetation - natural grasslands and sparsely vegetated areas and alpine environment in the Tatra Mountains. Due to location and terrain with highly variable altitude the climate of the region is very diverse. Mountain ranges are significant climate ranges of the region and together with rugged terrain substantially affect particular components of climate. Studied location lies largely in the area with cold continental climate, the river (Orava, Váh, Poprad) valleys have a slightly warmer climate and belong to moderately warm climate zone. The average annual temperature is $2.4-6{ }^{\circ} \mathrm{C}$ and decreases with higher altitude. In elevation $1000 \mathrm{~m}$ a.s.l. reaches the average values of 4 to $5{ }^{\circ} \mathrm{C}$, in $2000 \mathrm{~m}$ is about $-1{ }^{\circ} \mathrm{C}$ and on the High Tatras peaks is in average below $-3{ }^{\circ} \mathrm{C}$. Average summer temperature in July and August in basins reaches 16 to $18^{\circ} \mathrm{C}$, in the mountains, depending on altitude, less than $15^{\circ} \mathrm{C}$. The number of summer days with temperatures above $25^{\circ} \mathrm{C}$ is small: 20 to 40, and 0 in the hilltops. Mountains in northern Slovakia are generally richer in atmospheric precipitation (up to $2000 \mathrm{~mm}$ ), relatively low rainfall is in localities in so called "rain shadow of the mountains" (less than $350 \mathrm{~mm}$ ). The average rainfall in the area is $550-700 \mathrm{~mm}$.

\section{Sample collection}

In total 183 red foxes (Vulpes vulpes) as the most abundant freeliving carnivores were hunted during the monitoring of antirabic vaccination effect. 110 individuals were captured in southeastern Slovakia (Košice region), 73 specimen originated from northern part of territory (Žilina and Prešov regions). The hearths, lungs, and spleens were removed by the dissection at the State Veterinary and Food Institutes, delivered to the Institute of Parasitology SAS and stored by $-20^{\circ} \mathrm{C}$ until examination.

\section{Methods used}

During helminthological autopsy the hearts and lungs were examined for the presence of adult $D$. immitis. Due to lack of fresh blood and animal carcasses Dirofilaria spp. survey was based on molecular techniques. The total genomic DNA for PCR analyses was extracted from fox spleens using commercial isolation set DNeasy Blood and Tissue Kit (Qiagen $®)$. The amplification of the fragments of cytochrome oxidase subunit 1 (CO1) gene was 


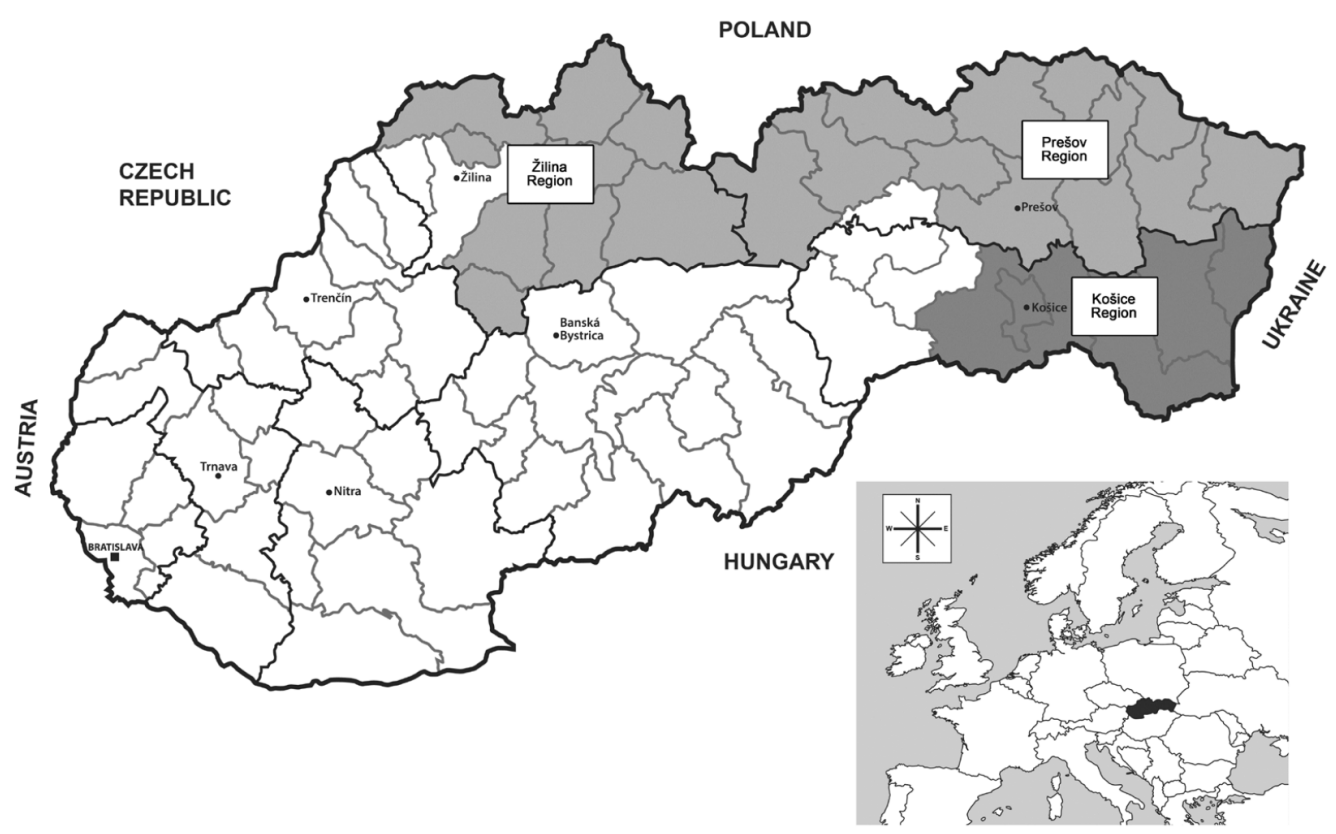

Fig. 1. The origin of foxes investigated for dirofilariosis in Slovakia

performed using specific $D$. repens, $D$. immitis, and Acantocheilonema recognitum pairs of primers according to Rishniw et al. (2006).

After amplification selected products (one isolate from three different localities, i.e. Košice, Michalovce and Prešov) were purified using NucleoSpin® Gel and PCR Clean-up kit (Macherey-Nagel) and sequenced on Applied Biosystems $A B I$ PRISM 3100-Avant DNA Sequencer. In order to elucidate any homologies with previously deposited sequences in Gen Bank, we conducted a BLAST search (www.ncbi.nih.gov/BLAST/). Next the multiple alignment was done by the use of CLUSTAL W implemented to MEGA 5.0 package (Tamura et al., 2007). The neighbor-joining ( $\mathrm{NJ}$ ) tree was constructed using MEGA 5.0 software. The evolutionary history of the isolates from Slovakia was inferred using the Maximum Likelihood method. Evolutionary analyses were conducted in MEGA5 (Tamura et al., 2007).

\section{Results}

No adult $D$. immitis worms were found during helminthological autopsy of 183 fox lungs and hearts.

The PCR analyses using species specific primer pairs revealed the presence of $D$. repens DNA in 105 out of 183 investigated foxes, $D$. immitis and $A$. recognitum were not confirmed in fox samples. The overall prevalence of vulpine dirofilariosis of $57.4 \%$ with great regional difference $\left(X^{2}=53.163 ; p<0.001\right)$ was observed. Most positive foxes (87 out of 110 ) were hunted in region of the south-eastern Slovakia, where the prevalence reached $79.1 \%$. Also in northern, highland region 18 of $73(24.6 \%)$ of foxes were infected with $D$. repens (Fig. 1).

As a result of sequencing of partial gene of $\mathrm{COI}$ we obtained the sequences similar in length and amounting respectively: $D$. repens $\mathrm{Ml}-209 \mathrm{bp}, D$. repens $\mathrm{KE}-203 \mathrm{bp}$ and D. repens $\mathrm{PO}-$ $202 \mathrm{bp}$. The BLAST analysis of our three sequences show $100 \%$

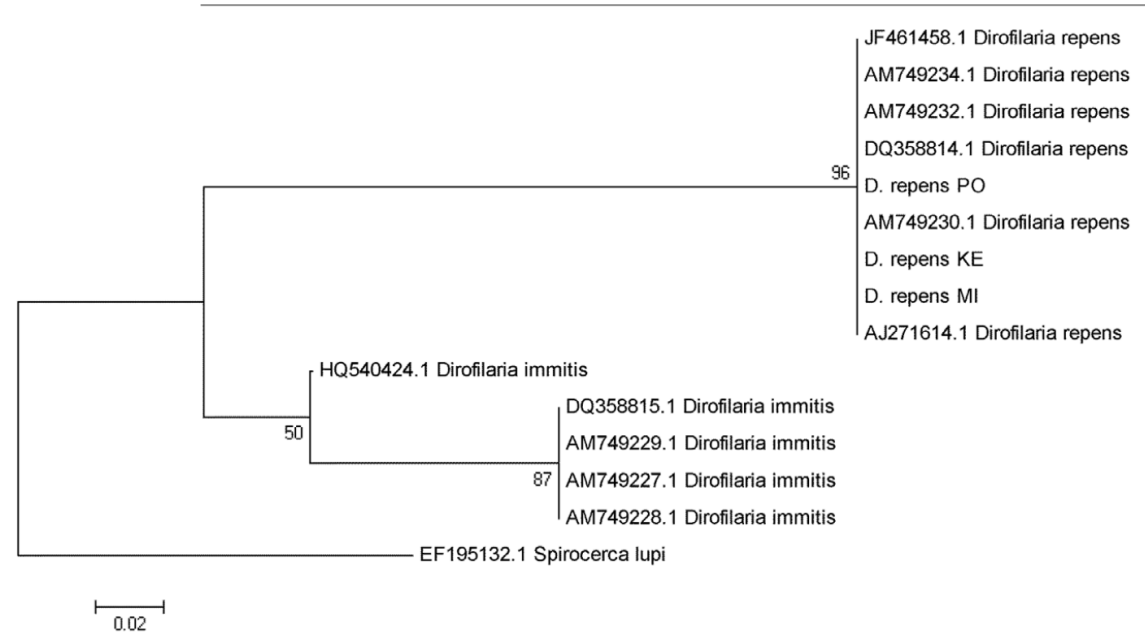

Fig. 2. Reconstruction of phylogenetic relationships within Dirofilaria based on partial sequences of COI mtDNA. The evolutionary history was inferred by using the Maximum Likelihood method based on the Tamura-Nei model, the bootstrap consensus tree inferred from 1000 replicates 
similarity, in the overlapping regions, between all isolates from foxes and with sequences of Dirofilaria repens isolated from humans (AM749234, JF461458), cats (AM749232) and dog (AM749230). The evolutionary history based on COI was inferred by using the Maximum Likelihood method based on the TamuraNei model (Fig. 2). The final alignment of $\mathrm{COI}$ sequences of the representatives of Dirofilaria was 202 bp long, where 41 characters were variable and 24 parsimony informative. The out-group for phylogenetic analysis was Spirocerca lupi (EF195132.1) (Fig. 2).

\section{Discussion}

The results of epidemiological research on vulpine dirofilariosis showed 105 out of 183 examined individuals from Slovakia $(57.4 \%)$ being infected with $D$. repens, that confirms that red fox as the most abundant wild canine predator is an important natural reservoir of the parasite. Several authors affirm the role of this carnivore in epidemiological chain of dirofilariosis (Mańas et al. , 2005; Magi et al., 2008, 2009; Marks \& Bloomfield, 1998). Dirofilarosis caused by $D$. immitis was also detected in other wild carnivore species - in wolves, coyotes, dingoes, raccoons, and black-footed ferrets (Pascucci et al., 2007; Custer \& Pence, 1981; Starr \& Mulley, 1988; Nakagaki et al., 2000; Wisely et al., 2008). A beech marten naturally infected was also found in Slovakia (Miterpáková et al., 2013). These finding indicate that the role of natural reservoir may play many carnivore species that occur in endemic areas.

The red fox is one of most numerous free living carnivores in Europe. A significant increase of vulpine population was in last decades observed in almost the whole European area after the oral rabies vaccination campaigns. Similar situation was recorded also in Slovakia. While in 1993 the spring stock was 6154 animals, in 1996 this number increased to 13331 foxes, 18920 in 2003 and 29530 individuals were counted in spring stock in 2011 (National Forest Centrum, 2011). From the epidemiological point of view, multiple accumulation in fox numbers and their urbanization mean, that the host is most accessible both for vectors and parasites, which may result in the increase in prevalence. Our finding of the large numbers of foxes infected with $D$. repens adverts to the role of this host in the circulation and transmission of dirofilariosis in wildlife. Magi et al. (2008) reported that in central Italy is in foxes more incident genus Acantocheilonema as Dirofilaria species and assume that this is due to the distribution of ticks as vectors of filariae from the genus Acanthocheilonema, whereas mosquitoes that transmit Dirofilaria spp. are in this area regularly and targeted regulated. Nevertheless, this is not the case in Slovakia, where the mosquito population is not controlled. Most noticeable is the situation on the lowlands in the south of territory, where floods occur frequently accompanied by mass occurrence of mosquitoes.

According to monitoring of mosquito species composition, 23 out of 50 in Slovakia known species are ranging in the Eastern Slovak territory. The most important are blood sucking plague with calamity occurrence, i. e. Aedes vexans, Culex pipiens, Ae. cinereus, Ae. rossicus, Ochlerotatus sticticus, and 0 . cantans with the first two mentioned being the most frequent species also in other parts of Slovakia (Strelková \& Halgoš, 2012). Further- more, Bocková et al. (2013) using molecular approaches diagnosed the presence of $D$. repens DNA in pooled samples from $A e$. vexans from eastern Slovakia. Ae. vexans is an inland floodwater mosquito species that habits in yards, fields, wooded areas and bites during night, at dusk and dawn but in shaded areas also during day. It has been proved that $A e$. vexans bloodmeals most frequently from mammalian hosts, including canids and humans thus this species is a suitable vector for Dirofilaria transmission. Mosquitoies from the genera Aedes and Culex may produce multiple generations, whereas Aedes vexans utilizes fresh floodwater habitats and lays desiccation-resistant eggs in ground depressions inundated by fresh floodwater. According to Trpiš and Shemanchuk (1970), the most suitable temperature for larval development of Aedes vexans is $25^{\circ} \mathrm{C}$. At this temperature, $86 \%$ of the larvae survive and pupate in 7 days. At $10^{\circ}$, $15^{\circ}, 20^{\circ}$, and $30^{\circ} \mathrm{C}$ larval development time is $46,22,10$, and 8 days. In water at $25^{\circ} \mathrm{C}$ the adults emerge in 2 to 5 days. It stands to reason that long periods of high temperatures enable the development of several generations of the vector during the summer season, when conditions are also suitable for the rapid development of parasite larval stages, leading to increased parasite biomass in the environment and escalating the likelihood for formation of new natural foci.

The development of larvae in intermediate host depends significantly upon environmental temperature, which must be higher than $14^{\circ} \mathrm{C}$. At this temperature, larvae in the mosquito's body merely survive without developing further. With increasing temperature increases also the rate of development. At $16{ }^{\circ} \mathrm{C}$ infectious stages appear after 43 days, at $22^{\circ} \mathrm{C}$ in $16-22$ days, and at temperatures above $28^{\circ} \mathrm{C}$ as early as after 3-4 days (Fortin \& Scolombe, 1981).

The result of our initial survey of dirofilariosis in red foxes showed a high prevalence of the disease in the carnivore population from southeastern Slovakia $(79.1 \%)$, in the area, where climatic conditions favor both, the occurrence of vector and parasite development in its organism (Iglódyová et al., 2012). Previous research confirmed in this area $34.5 \%$ of dogs being infected with subcutaneous dirofilariosis and the presence of $D$. immitis was also confirmed. Finding of $24.6 \%$ infected foxes in northern and colder regions, where already also autochthonous cases of canine dirofilariosis were recorded adverts to the substantiality that the environmental circumstances in these areas are also favorable for the presence of both, parasite and vector.

According to data from the Slovak Hydrometeorological Institute, during the study period 2007-2009 above-normal summer temperatures were observed. Actually, the average daily temperature in July and August 2007 and 2008 overcame historical maximum since 1871 and the deviation from the long-term average reached +2 to $+3.1{ }^{\circ} \mathrm{C}$ throughout entire Slovakia. Furthermore, in these year was above-average warm June when also in northern regions temperatures in valleys reached $+15^{\circ} \mathrm{C}$ and higher. During summer seasons occurred several periods of a sequence of very warm even tropical days with temperatures over $25^{\circ} \mathrm{C}$ and frequent storm after heat spells, which allowed the development of infective larvae and over-infestation of vectors. Here at, in mountains with plenty of wooded areas the desiccation of temporary water reservoirs during prolonged dry with heat days is less intense than in agricultural areas with cultural steppe, which 
favors the continuation of both, vector and parasite life cycles and extends the period of infection risk.

Another factor that has to be taken into consideration for a comprehensive assessment of dirofilariosis epidemiology is the possibility of parasite importation via infected dogs. In the northern part of Slovakia there are several natural parks that are favorite destinations for tourist from our and neighboring countries. People are during outdoor activities often accompanied by their dogs and it is possible that $D$. repens was introduced into northern region by infected dogs from endemic regions. Abundance of vectors, wildlife reservoir hosts and suitable environmental conditions allowed the continuation of parasite life cycle in natural conditions, practically beyond control.

All above mentioned circumstances are inevitably to be considered for the proper timing of chemoprophylaxis in domestic carnivores to provide the protection against infection. In these newformed endemic foci, in particular, it is important to create awareness of professional public as previous findings disclosed a very low level of information in this important group.

\section{Acknowledgements}

The work was supported by the Science Grant Agency VEGA 2/0011/12 and by the Application Center for Protection of Humans, Animals and Plant against Parasites (ITMS Code: 26220120018) based on the support of the Operational Programme "Research \& Development" funded from the European Regional Development Fund (rate 0.2) and bilateral project of Slovak Research and Development Agency No. SK-PL-0098-12.

\section{References}

BockovÁ, E., RudOLF, I., KočIŠOVÁ, A., BETÁŠOVÁ, L., VenclíkOVÁ, K., MENDEL, J., HUBÁleK, Z. (2013): Dirofilaria repens microfilariae in Aedes vexans mosquitoes in Slovakia. Parasitol. Res., 112: 3465 - 3470. DOI: 10.1007/s00436-013-3526-9

Confalonieri, U., Menne, B., AkHtar, R., Ebi, K.L., Hauengue, M., Kovats, R.S., Revich, B., WoodWard, A. (2007): Human health. Climate Change 2007: Impacts, Adaptation and Vulnerability. In: PARRY, M.L., CANZIANI, O.F., PALUTIKOF, J.P., VAN DER LINDEN, P.J., HANSON, C.E. (Eds) Contribution of Working Group II to the Fourth Assessment Report of the Intergovernmental Panel on Climate Change. Cambridge University Press, Cambridge, UK, 391 - 431

Custer, J.W., Pence, D.B. (1981): Dirofilariasis in wild canids from the Gulf coastal prairies of Texas and Louisiana, U.S.A. Vet. Parasitol. 8: 71 - 82. DOI: 10.1016/0304-4017(81)90019-4

Fók. E. (2012): The spreading of Dirofilaria infections in Eastern European countries. In: G. GRANDI, L. KRAMER, C. GENCHI (Eds) Proceedings of Third European Dirofilaria Days, June 21 - 21, 2012, Parma, Italy: 21

FORTIN, J.F., SCOLOMBE, J.O.D. (1981): Temperature requirements for the development of Dirofilaria immitis in Aedes triseriatus and Ae. vexans. Mosquito News, 41: $625-633$

GENCHI, C., KRAmER, L.H., RIVASI, F. (2011): Dirofilarial infections in Europe. Vector borne Zoonotic Dis., 11: 1307 - 1317. DOI: $10.1089 / v b z .2010 .0247$
IglódyovÁ, A., MiterpákovÁ, M., HuRníkovÁ, Z., AntolovÁ, D., DUBINSKÝ, P., LETKOVÁ, V. (2012): Canine dirofilariosis under specific environmental conditions of the Eastern Slovak Lowland. Ann. Agric. Environ. Med., 19: 57 - 60

Magl, M., Calderini, P., Gabrielli, S., Dell'Omodarme, M., PRATI, M.C., CANCRINI, G. (2008): Vulpes vulpes: A possible wild reservoir for zoonotic filariae. Vector-Borne Zoonotic Dis., 8: 249252. DOI: 10.1089/vbz.2007.0207

Magi, M., Macchioni, F., Dell'Omodarme, M., Prati, M.C., CalderinI, P., Gabrielli, S., IORI, A., Cancrinl, G. (2009): Endoparasites of Red Fox (Vulpes vulpes) in Central Italy. J Wildl Dis., 45: 881- 885. DOI: 10.1556/AVet.2013.029

MAŃAS, S., FerRer, D., CASTELLA, J., LÓPEZ-MARTíN, J.M. (2005): Cardiopulmonary helminth parasites of red foxes (Vulpes vulpes) in Catalonia, northeastern Spain. Veterinary J., 169: 108 - 120. DOI: 10.1016/j.tvjl.2003.12.011

MARKS, C.A., BLOOMFIELD, T.E. (1998): Canine hearthworm (Dirofilaria immitis) detected in red foxes (Vulpes vulpes) in urban Melbourne. Vet. Parasitol., 78:147 - 154

Miterpáková, M., Antolová, D., HuRníkovÁ, Z., DuBinskÝ, P. (2008): Dirofilariosis in Slovakia - a new endemic area in Central Europe. Helminthologia, 45: 20 - 23. DOI: 10.2478/s11687-0080003-6

Miterpáková, M., HuRníKovÁ, Z., Zaleśny, G., ChovancovÁ, B. (2013): Molecular evidence for the presence of Dirofilaria repens in beech marten (Martes foina) from Slovakia. Vet. Parasitol., 196 (3 - 4): 544 - 546. DOI: 10.1016/j.vetpar.2013.02.028.

MORGAN, E.R., WALL, R. (2009): Climate change and parasitic disease: farmer migration? Trends Parasitol., 25 (7): 308 - 313.

NAKAGAKI, K., SuZUKI, T., HAYAMA, S.I., KandA, E. (2000): Prevalence of dirofilarial infection in racoon dogs in Japan. Parasitol. Int., 49: 253 - 256. DOI: S1383-5769

NATIONAL FOREST CENTRUM (2011): Hunting Statistical Yearbook of the Slovak Republic. Retrieved from http://www.forestportal.sk (In Slovak)

Pascucci, I., Fico, R., D’Angelo, A.R., Serini, S., Camma, C. (2007): First notification in Italy of cardiopulomonary filariosis (heartworm disease) in a wolf (Canis lupus). Vet. Ital., 43: 851 858

Rishniw, M., BarR, S., Simpson, K., Frongillo, M., Franz, M., DOMINQUEZ ALPIZAR, J. (2006): Discrimination between six species of canine microfilariae by a single polymerase chain reaction. Vet. Parasitol., 135: 303 - 314. DOI: 10.1016/j.vetpar.2005.10.013

SIMON, F., MORCHON, R., GONZALES-Miguel, J., MARCOSATXUTEGI, C., SILES-LUCAS, M. (2009): What is new about animal and human dirofilariosis? Trends Parasitol., 25: 404 - 409. DOI: 10.1016/j.pt.2009.01.003

StARR, T.W., MuLleY, R.C. (1988): Dirofilaria immitis in the Dingo (Canis familiaris dingo) in a Tropical Region of the Northern Territory, Australia. J. Wildl. Dis., 24: 164 - 165

StrelkovÁ, L., Halgoš, J. (2012): Mosquitoes (Diptera, Culicidae) of the Morava River floodplain, Slovakia. Centr. Eur. J. Biol., 7: 917 - 926. DOI: 10.2478/s11535-012-0061-0

SvobodovÁ. S., SvobodovÁ, Z., BeladičovÁ, V., VAlEntovÁ, D. (2005): First case of canine dirofilariasis in Slovakia: a case report. Vet. Med. Czech., 50: 510 - 512 
TAMURA, K., Dudley, J., NeI, M., KUMAR, S., MEGA4 (2007): Molecular Evolutionary Genetics Analysis (MEGA) software version 4.0. Mol. Biol. Evol., 24: 1596 - 1599. DOI: 10.1093/molbev/msm092

TRPIŠ, M., SHEMANCHUK, J.A. (1970): Effect of constatnt temperature on the larval development of Aedes vexans (Diptera: Culicidae). Canadian Entomol., 102: 1048 - 1051
Wisely, S.M., HoWARD, J., Williams, S.A., Bain, O., SANTYMIRE, R.M., BARDSLEY, K.D., WILLIAMS, E.S. (2008): An unidentified filarial species and its impact on fitness in wild populations of the Black-Footed Ferret (Mustela nigripes). J. Wildl. Dis., 44: 53 - 64. ZELL, R. (2004): Global climate change and the emergence/reemergence of infectious diseases. Int. J. Microbiol., 37: 16 - 26. DOI: 10.1016/S1433-1128(04)80005-6 